\title{
Social and genetic implications of customary consanguineous marriage among British Pakistanis. Report of a meeting held at the Ciba Foundation on 15 January 1991
}

Most societies share an incest taboo outlawing marriage or sexual relations with first degree relatives (parents, sibs, or children). In addition, some discourage marriage between more distant relatives (consanguineous marriage) by religious or legal sanctions. The underlying reasons for such prohibitions seem mainly social and anthropological, but attitudes are often coloured by the incest taboo. Many other societies favour consanguineous unions, the commonest being marriages between uncle and niece, first cousins, first cousins once removed, or second cousins. Obviously, when groups with different attitudes towards consanguineous marriage come into contact there is ample scope for prejudice. This meeting brought together clinical and human geneticists, anthropologists, counsellors, and representatives of the British Pakistani community, in order to disentangle fact and prejudice in social and medical attitudes to customary consanguineous marriage among British Pakistanis.

\section{The British Pakistanis}

British Pakistanis now number over 400000 , with about 12500 births a year. The majority originate from the Mirpur area of Kashmir, where a large rural population was displaced in the 1960 s to build a dam. Migration was initiated by men taking work in towns in the north of England. Wives followed on average 10 years later, so births have been occurring proportionately only since the late 1970 s. The need for maternal and child health services, including pregnancy screening and genetic counselling, is therefore both recent and growing.

Both in Pakistan and the UK about $75 \%$ of marriages are between relatives, but the frequency of closely consanguineous marriage has increased with migration, about $55 \%$ of couples of reproductive age in England being married to a first cousin. In many cases the relationship is closer than first cousins because of previous consanguineous marriages in the family. The proportion of cousin marriages is likely to fall but the absolute number will increase, at least for the next generation, because the population is growing.

Perinatal mortality among British Pakistanis is about 19/1000 (like the UK population in 1970), and is not falling as rapidly as in other ethnic groups. This may be the result of a combination of several factors, including genetic problems related to consanguineous marriage.

\section{The problem}

Consanguineous marriage is disapproved of in most of Europe, ostensibly on health grounds. Prejudice is strong and health workers are by no means exempt. The relatively high perinatal and infant mortality among British Pakistanis is widely attributed to the genetic effects of consanguineous marriage, the implication being that the custom should be discouraged, and health workers frequently tell consanguineous parents of children with a congenital disorder that their child is sick because they are related. There is thus a consistent pressure on British Muslims against the custom, explicitly reinforced in 1990 by an item on the BBC Asian programme East, which is viewed by most British Indians and Pakistanis. There is growing evidence that grossly exaggerated ideas of the deleterious effects of consanguineous marriage are becoming current.

In medicine the first obligation, even before doing good, is to avoid doing harm, but for the British Pakistani population at the moment, medical contacts involving the implications of consanguineous marriage are generally traumatic, with destructive impact reverberating throughout the family ( $\mathrm{Dr}$ Nadeem Qureshi). These attitudes are being exported to the Middle East and Asia, where media campaigns against cousin marriage are being set up on eugenic grounds, despite the fact that the dangers 
of eugenic policies have been amply shown in the past, and without any consideration of the social role of customary consanguineous marriage.

\section{Genetic implications of consanguineous marriage}

Consanguineous marriage increases the risk of offspring with congenital malformations or recessively inherited disease, but does not significantly affect the incidence of chromosomal disorders or diseases with dominant or $\mathrm{X}$ linked inheritance. For unrelated couples the general risk of stillbirth, neonatal or childhood death, or congenital malformation is about $2.5 \%$. In general, a first cousin couple have about twice this risk. There is also an increased risk of some degree of mental handicap.

In counselling relatives who wish to marry, a clinical geneticist attempts to distinguish couples with and without a possible family history of inherited disorder. When there is evidence of genetic disease within the family, the couple's risk of having similarly affected children is calculated, and they are offered carrier testing and prenatal diagnosis when these are available. In the majority of cases, however, there is no evidence of a serious familial disorder. Such couples are informed of the above general risk, and most find the discussion reassuring and proceed to have a family. There seems little reason to give different advice to members of groups where consanguineous marriage is particularly common.

\section{Global distribution and frequency of consanguineous marriage}

A recent study (Dr Alan Bittles) shows that at least $20 \%$ of the world population favours the custom, at least $6.5 \%$ of couples actually make a consanguineous marriage, and at least $8.4 \%$ of all infants born have consanguineous parents. Customary consanguineous marriage is often, but by no means always, associated with the Muslim religion: in Southern India it is favoured by Hindus, Christians, and Muslims alike, but it is uncommon among the large Muslim population of Indonesia. In Japan the incidence has fallen markedly in the last $\mathbf{4 0}$ years, but there is no evidence of a similar decline elsewhere.

A custom that is so popular obviously has important social functions. These are related to kinship pattern, and are not always obvious to members of different societies. Dr Roger Ballard showed that the typical north European kinship pattern (which is very ancient) is 'ego-centric'. Kinship is defined in relation to each person, the primary circle consists of first degree kin, and when a couple marry, first degree relatives of both partners are adopted as additional kin. Thus, society is composed of numerous small overlapping units that change with generations, a structure that may favour flexibility, mobility, and social cohesion.

By contrast, in much of the world including the Middle East, North Africa, and the Indian subcontinent, kindreds are patrilineal, that is, defined by the male line of descent from a common ancestor. A person is identified by their place in this large family group, which is often also patrilocal, that is, the males and their descendants stay together. Women leave their family of birth to enter their husband's kindred, often with transfer of bride price or dowry. The population is made up of many sizeable, rather exclusive groups, each with a strong internal network of obligations.

Patrilineal kinship groups fall further into two broad categories depending on where the women customarily come from. Often they are obtained from unrelated families or tribes (exogamy). The traffic may be controlled by complex rules, as in many Hindu castes. Women's power position may be relatively weak, and when dowry is paid, a girl can represent a net burden on her family of birth. Alternatively, women may be obtained from within the extended family or tribe (endogamy), that is, the group favours consanguineous marriage. This pattern minimises both associated financial transactions and transfer of members between groups, so strengthening the identity of, and obligations within, the kinship group and setting it off more clearly from the wider society. These families are to some extent matrilineal as well as patrilineal: daughters are not a burden because a balanced sex ratio is desired within the extended family group, and they are unlikely to be exploited by a mother in law who is also an aunt.

Some of the family implications were observed in a study of British Pakistani families with thalassaemic children (Dr Aamra Darr). She noted that "in no case did a husband overrule his wife's decision on whether to terminate a pregnancy or not; none of the women were blamed for the disease; both parents discussed the issue openly; little stigma was attached to having an inherited disease in the family, and no interest was shown in fetal sexing". Her conclusion was that "support structures for women as well as men and children are inherent in the kinship pattern of societies that practice consanguineous marriage. These structures are in effect created by that marriage pattern".

By contrast, in many Hindu families, marked stigma is attached to inherited disease ( Dr B Modell). Women can be blamed for bringing sickness into the family, and some hide their child's illness even from their own parents or sisters, becoming isolated and depressed. In addition, 
Indian Hindus sometimes request fetal sexing to avoid a female child.

It is clear that any approach to helping with the genetic implications of customary consanguineous marriage should avoid criticisms and take the above social benefits into account.

\section{Genetic implications of customary consanguineous marriage}

Most studies of the genetic implications have of necessity been conducted in countries with a high background infant and childhood mortality that differs by area and social class. Since consanguineous marriage is commoner among lower socioeconomic groups, it is not surprising that few studies have produced convincing statistical information on its health implications. This in itself shows that bars on cousin marriage cannot have been introduced on health grounds, but must have social origins.

The clearest statistical study to date was conducted in the 1960 s by Schull and Neel in Japan. They observed an increase of cumulative mortality from 9 to $10.5 \%$ and a roughly $30 \%$ increase in congenital defects among children of consanguineous parents. There were also small differences in height, weight, and school achievement, detectable only by very careful measurement.

\section{Observations in the UK}

Genetic problems emerge as important causes of death and disability only when the infant mortality is low: they may emerge earlier in communities with a tradition of-consanguineous marriage than in others. Migration from a developing to a developed country is accompanied by a dramatic fall in infant mortality from over $10 \%$ to less than $2 \%$. Since statistics are reliable and most children with chronic disorders are diagnosed, the British Pakistani population provides a unique opportunity for studying the genetic implications of consanguineous marriage.

The interim results of a prospective study currently under way in Birmingham (Dr Sarah Bundey) confirm that British Pakistanis are a population at high genetic risk, the overall rate of chronic disability being more than twice that in non-Pakistanis. These risks are mainly concentrated among the couples in a consanguineous marriage, and probably in a limited number of families within this group.

\section{Possibilities for prevention}

Families can be helped to avoid the birth of children with serious congenital disorders by family counselling, screening before and during pregnancy, prenatal diagnosis, and selective abortion of affected fetuses. The limited studies available indicate that when a major fetal abnormality is identified British Pakistani mothers request termination of pregnancy at a rate comparable to others, so recommendations including the option of prenatal diagnosis are equally applicable. However, a study of services for thalassaemia has shown gross deficiencies in the delivery of genetic screening and counselling to British Pakistanis. As they are quite scattered, recommendations for correcting this situation apply for most health regions and most clinical genetics services.

\section{Recommendations}

Firstly, it is necessary for clinical geneticists and managers to be aware of the importance of the issue and the feasibility of a culturally acceptable approach. The next crucially important requirement is for trained Punjabi speaking counsellors to be attached to relevant genetics centres. Clear information is needed for the British Pakistani population, and for health workers, on the nature and limits of the genetic risk associated with consanguineous marriage, steps that can be taken to minimise it, how to obtain advice, and the role of clinical geneticists. Specific steps are also needed at many levels of the health service.

When consulted, general practitioners need to give correct information and take a family history. If there is any suspicion of genetic disease in the extended family, the couple should be referred to a clinical geneticist. If there is no such suspicion, the couple can be informed that their risk of having a child with a congenital disorder is two to three times that of the rest of the population. However, their chance of a completely healthy child in each pregnancy is about $90 \%$; many problems can be managed successfully, and others can be avoided by appropriate screening before and during pregnancy. They should be offered tests for thalassaemia and sickle cell trait (and CF testing when available), advised on avoiding environmental risks to pregnancy (dietary deficiencies, anaemia), tested for immunity to rubella infection, and given the opportunity to consult a clinical geneticist if they wish.

All the above steps are even more important in early pregnancy. Obstetricians should provide similar information, and all consanguineous couples should be offered expert fetal anomaly scanning, with appropriate counselling.

British Pakistani families presenting to paediatricians with a child with an inherited disease should be followed up as far as possible, in consultation with a clinical geneticist, as investigation of other family members may permit many carriers and couples at risk to be identified and counselled before they have affected children. 


\section{Conclusion}

Though the British Pakistani tradition of consanguineous marriage has important genetic implications, the negative aspects have been exaggerated, causing unnecessary distress to families and the population. The genetic implications need to be seen in context, and criticisms and efforts to disrupt traditional marriage patterns should be avoided. British Pakistanis have a special need for an informed approach by general practitioners, obstetricians and paediatricians, an optimal genetics service, and counselling that is sensitive to social and cultural background.

The genetics service required does not differ in any important way from that recommended for the general population. Though preventive genetics services save money, they are as yet far from fully implemented. The consequent avoidable suffering and economic losses are particularly conspicuous, and the benefits of implementation would be correspondingly great, in areas with a significant British Pakistani population.

B MODELL Perinatal Centre, Department of Obstetrics and Gynaecology, University College London, 86-96 Chenies Mews, London WC1E $6 \mathrm{HX}$. 